\title{
El derecho a la verdad en el marco de la justicia transicional como obligación del Estado mexicano ante la impunidad ${ }^{1}$
}

\author{
The right to the truth in the context of transitional justice as an obligation \\ of the mexican State in the face of impunity
}

Laura Wendy Zazueta Carrillo ${ }^{2}$

Fecha de recepción: 12 de junio de 2014

Fecha de aprobación: 20 de agosto de 2014

\section{RESUMEN}

Se aborda el derecho a la verdad como obligación del Estado, a partir de los principios y elementos que rigen al estado social y democrático de derecho como garante de derechos fundamentales. Se analiza la trascendencia del derecho a la verdad como derecho humano fundamental en el marco de la justicia transicional como obligación del estado de proteger los derechos fundamentales, investigar, sancionar y reparar a las víctimas ante la desaparición forzada o involuntaria.

Palabras clave: derecho a la verdad, justicia transicional, desaparición forzada.

1 El articulo es producto del proyecto de investigación "El Derecho a la Verdad en la Justicia Transicional", gestionado en la Facultad de Derecho y Ciencias Políticas de la Universidad de Juarez del Estado de Durango. Dicho Proyecto fue financiado con el apoyo económico de la citada Universidad.

2 Doctora en Derecho - Universidad Juárez del Estado de Durango Docente - investigadora de la Facultad de Derecho y Ciencias Políticas de la Universidad Juárez del Estado de Durango. Correo Electronico: lawezaca@ hotmail.com 


\begin{abstract}
The right of truth is approached as an obligation of the State, from the principles and elements that govern the social and democratic rule of law as guarantor of fundamental rights. The importance of the right of truth is analyzed as a fundamental human right in the context of transitional justice as obligation of the state to protect fundamental rights, investigate, punish and repair the victims in forced or involuntary disappearance.
\end{abstract}

Keywords: Right to the truth, transitional justice, enforced disappearance

\title{
INTRODUCCIÓN
}

El derecho a la verdad se originó en la necesidad individual de conocer el paradero de seres queridos ante desapariciones forzadas o involuntarias y fue evolucionando a tal grado que por su vigencia es considerado como un derecho humano fundamental especialmente en el marco de la justicia transicional, atento a que el derecho a la verdad, además de una obligación del Estado, es quizá el principal objetivo a alcanzar por los mecanismos de justicia transicional.

Es responsabilidad fundacional del Estado proveer seguridad a la vida y patrimonio de las personas. Tanto la presencia delictiva como la sensación creciente de inseguridad tiende a reproducirse en la medida en la que el Estado se muestra incapaz de combatir las acciones contrarias a la ley, lo que se traduce en sistemas de justicia deficientes, impunidad que alienta la propagación de la corrupción en diversas esferas de gobierno, socava instituciones públicas, estrecha lazos de complicidad, ante todo: vulnera la seguridad. La impunidad constituye el principal aliento delictivo, siendo la desaparición de las personas una de la agresiones más dolorosas para la sociedad.

En virtud de que las desapariciones forzadas han aumentado con "la guerra contra el crimen organizado" y el narcotráfico, y que la falta de políticas de prevención, investigación y castigo contribuyen la impunidad, el fenómeno delictivo se integra al 
discurso político a la vez que se incorpora a las agendas públicas, a los movimientos sociales y por supuesto, cobra relevancia en las investigaciones académicas.

Atento a la victimización real o al temor de sufrir alguna acción delictiva, es cuestionable la capacidad del Estado para constituirse en garante de la seguridad de las personas.

Si hay impunidad en México es porque hay corrupción, todas las estadísticas disponibles nos permiten concluir que no se respetan los derechos fundamentales de los ciudadanos, la impunidad alcanza cifras impresionantes.

Por ello, es cuestionable si existe un marco legal y políticas públicas para determinar la suerte o el paradero de las víctimas de desapariciones forzadas o involuntarias, sancionar a los responsables y garantizar el derecho a la verdad.

\section{ESTADO Y DERECHO}

Hesse (2001, p.89) refiere que los derechos fundamentales deben crear y mantener las condiciones elementales para asegurar una vida en libertad y la dignidad humana. Ello solo se consigue cuando la libertad de la vida en sociedad resulta garantizada en igual medida que la libertad individual, ambas se encuentran relacionadas. Además, considera que un problema dentro de la política contemporánea de los derechos fundamentales consiste en la necesidad de amparo estatal.

Bajo esta tesitura, Benda (2001) precisa que

el Estado debe proteger activamente la dignidad humana, hacer frente a las amenazas que surjan en el curso de los cambios sociales, también está obligado a detectar a tiempo futuras amenazas y a actuar en consecuencia, en tanto la previsión o el auxilio que resulten posibles, en virtud que el Estado debe estar bajo el imperio del Derecho (p. 126).

Uno de los temas que más preocupa a nuestra sociedad, es el respeto que el Estado debe garantizar a los derechos y en consecuencia, a la integridad de sus gobernados. 
En tal virtud, los derechos a la vida, a la libertad, a la libre manifestación de las ideas, a la libertad de asociación, y a los principios de seguridad jurídica y de un debido proceso, son imprescindibles de un Estado de Derecho en el que las aspiraciones del ser humano son desarrollarse en condiciones dignas y socialmente favorables.

El Estado social de derecho, de acuerdo con Jiménez Campo (1984, p. 276) es “aquél en el que valiéndose frecuentemente de técnicas provenientes del Estado de derecho, promueve la consecución de una igualdad y libertades reales y efectivas para los individuos y los grupos en que éstos se integran”.

Una de las diferencias más importantes entre el modelo clásico del Estado liberal y el Estado constitucional contemporáneo es que en el Estado liberal se fortaleció la construcción de cuerpos legislativos cuya validez descansaba en el procedimiento de creación formal de las leyes, en tanto que el Estado constitucional supone la construcción argumentativa del derecho a fin de obtener coherencia constitucional de todo el orden jurídico, privilegiando especialmente los procesos constitucionales de defensa o control de la constitucionalidad (Atienza y Ferrajoli, 2005, pp.10 y ss.).

Jürgen Habermas (1989, p. 65) refiere que el Derecho “es el medio lingüístico, mediante el que se concatenan las interacciones y se estructuran las formas de vida”. En tal sentido, el derecho como instrumento de construcción humana resulta indispensable para la sociedad a fin de establecer normas básicas que garanticen un orden, cediendo parte de sus libertades a favor de una forma de organización comunitaria conocida como Estado.

Robert Alexy (Ferrajoli, 2006) afirma que el Estado constitucional y democrático de Derecho es el denominado constitucionalismo discursivo bajo cinco conceptos: los derechos fundamentales, la ponderación, el discurso, el control de constitucionalidad y la representación.

Para Ferrajoli (2006), el Estado constitucional y democrático de derecho surge a partir de las constituciones modernas y se caracteriza por el principio de legalidad y funcionalización de los poderes del Estado al servicio de la garantía de los derechos fundamentales de los ciudadanos. 
En virtud de estas aseveraciones, cabe señalar que, solo en un Estado constitucional y democrático se reconocen, respetan, practican, garantizan y satisfacen de manera efectiva los derechos fundamentales por las autoridades y por los particulares.

Un Estado democrático según Ferrajoli (2006, pp. 864-868) debe reflejar no sólo la voluntad de la mayoría, sino los intereses y las necesidades vitales de todos. En tal virtud, la democracia sería sustancial o social, un Estado de derecho dotado de garantías efectivas, tanto para liberales como sociales, y un Estado político representativo basado en el principio de las mayorías.

El Estado de derecho, apoyado en la teoría garantista, maximiza los derechos humanos reduciendo el papel punitivo del Estado, todo el ordenamiento está orientado por ellos. La validez jurídica implica el respeto y garantía de los derechos fundamentales, por lo que se deslegitima el derecho vigente secundario cuando no se ajuste a las normas constitucionales. Asimismo, el derecho será injusto si se aparta del respeto a los derechos fundamentales.

En este sentido, el Estado mexicano a partir de la Declaración Universal de los Derechos Humanos de 1948, ha signado y ratificado una serie de tratados de derechos fundamentales tanto en el sistema universal como en los sistemas regionales de protección de los derechos humanos, reconociendo que el ser humano tiene derechos intrínsecos a su dignidad y que él tiene la obligación de respetarlos y protegerlos.

Podemos subrayar, que si la legitimidad del Estado reside en el reconocimiento de un conjunto de derechos que imponen límites y vínculos al poder político, tal legitimidad estatal proviene tanto de los derechos fundamentales como de las políticas públicas que ofrezcan garantía efectiva a esos bienes jurídicos fundamentales.

Por tanto, no es suficiente el reconocimiento constitucional o normativo de los derechos fundamentales, son indispensables políticas públicas y mecanismos de garantía que los hagan efectivos.

En tal virtud, en el Estado social y democrático de derecho, los derechos fundamentales no se limitan a derechos públicos subjetivos, atento a las necesidades y 
formas de organización social y económica, surge una nueva percepción de derechos fundamentales, la sociedad se protege por el Estado y de él, reconociendo que los derechos fundamentales también despliegan sus efectos frente a los particulares, es decir, frente a terceros, lo que se ha denominado la eficacia horizontal.

\section{Derecho a la Verdad}

Para analizar el derecho a la verdad resulta indispensable en una primera instancia, revisar el significado de verdad.

Los filósofos trazan una distinción entre la verdad como cuestión social y como cuestión intelectual. La concepción relativa del derecho a la verdad correspondería a la primera categoría, a la verdad como cuestión social, atendiendo a que se trata de un concepto jurídico, de un derecho que el Estado debe reconocer al individuo.

Häberle (2006, pp. 1-4) advierte que el Estado constitucional debe hacer frente al problema sobre la importancia a la verdad, si su competencia y actuación descansa en el valor de la verdad del mismo modo como se afirma que por sus fundamentos está obligado a la justicia y al bienestar común. Siendo cuestionable si disponen los ciudadanos sobre un derecho a la verdad, si existe dentro de los derechos humanos uno que atañe propiamente a la verdad, o si debemos conformarnos sólo con la búsqueda de la verdad o constituye un sueńo fundar el Estado en la verdad.

Vaclav Havel (Häberle, 2006, p. 2) quien pasó de ser prisionero de la República Checoslovaca a presidente constitucional de la República Federal Checa fue el primero en exigir un "derecho a la verdad", confiriendo al cuestionamiento por la verdad una dimensión profundamente constitucional así como en la vida política.

Por la influencia de Havel, el problema de la verdad es un tema constitucional y no sólo tratado teoréticamente en forma "platónica". Desde el cambio político en Europa oriental a partir de 1989, lo que significó el paso de Estados totalitarios a Estados constitucionales, tiene que confrontarse la doctrina del Estado constitucional como 
el problema de la verdad y a introducir en el texto escrito algunos de sus aspectos más relevantes. Havel subraya que nunca pierde vigencia e importancia el principio relativo a que el ciudadano debe asumir su parte de responsabilidad en el destino de la sociedad entera y comportarse siempre conforme al espíritu de este principio: dar voz a la verdad, darla a conocer a todos los demás sobre todos los que detentan el poder, exigir de éste el respetar la verdad y crear con todos un espacio para que tengan lugar discusiones democráticas públicas, estimando que el poder incurre en la falsedad, porque es prisionero de algunas mentiras, el poder falsea el pasado, el presente y el futuro (Häberle, 2006, pp. 44-45).

Para Häberle (2006, pp. 124, 126-127), el Estado no puede anquilosarse en verdades preestablecidas, aunado a esto, el principio democrático excluirá que el Estado sea una verdad revelada y acabada; esto es, que tenga dominio absoluto y monopolio de la información con el fin de disponer de ella arbitrariamente. El principio de responsabilidad y el de la esfera pública, que satura las funciones del Estado, procura la franqueza y acercamiento a la verdad, lo que excluye la "verdad única" y la imagen total y fundamental del Estado. La democracia plural del Estado constitucional confronta el problema de la verdad especialmente a través de tres ámbitos distintos: la discusión sobre la relación entre verdad y mayoría, la compresión de la formación social de la opinión pública y, como parte de ésta, la limitación de la libertad de prensa en interés de la protección de otros valores y para dirigir sus informes a "conformarse a la verdad", en lugar de las mentiras mediáticas.

De estas libertades esenciales de la cultura, deriva a su vez el derecho fundamental a la verdad, como señala el mismo Häberle (2006):

El Estado constitucional presupone que las personas, es decir, los ciudadanos, tienen un interés en la "búsqueda de la verdad"; donde el interés por la verdad es ya la meta a alcanzar. Incluso tiene permitido el obligar -como última ratiobajo juramento a cumplir conforme a la verdad subjetiva, aunque esto no quiere decir que garantice la verdad objetiva. El Estado puede encomendar a sus funcionarios la búsqueda de la verdad, también crea comisiones parlamentarias o "comités particulares". Pero "ministerios de la verdad" quedan estrictamente prohibidos. El enorme significado que tiene el tercer poder como el intento 
más serio de buscar la verdad deviene de su forma legal de proceder (verdad y justicia como resultado de un proceso): independencia institucional y personal de los jueces, investigación por sospechas fundadas, postulado de la "búsqueda imparcial de la verdad”, transparencia como garantía conexa a la búsqueda de la verdad: condiciones de verdad (p. 133).

El derecho a la verdad es el derecho a obtener respuestas por parte del Estado. Todo individuo puede exigirle al Estado que lo informe acerca de aquello que le corresponde saber. Este derecho, presenta dos fases, una individual y otra colectiva. Esta última se asienta en el derecho de la comunidad a conocer su pasado, entre otras razones, como forma de resguardo hacia el futuro. "Es un derecho de la sociedad a conocer sus instituciones, sus actores, los hechos sucedidos, para poder saber desde el conocimiento de sus aciertos o de sus falencias, cual es el camino a seguir para consolidar la democracia" (Olveira y Guembe, 1998, p. 549).

En sentido individual nos referimos al derecho particular de los familiares a reclamar los cuerpos de sus seres queridos y a informarse sobre el destino que sufrieran.

El derecho a la verdad no constituye ninguna novedad, por el contrario, forma parte de antiquísimos deberes del Estado y de derechos de los individuos, por lo que está íntimamente ligado al derecho al duelo, a enterrar a los propios muertos, el respeto al difunto ha existido desde los orígenes de la humanidad.

Si cuestionamos el derecho al duelo es negar que un sujeto posee una dignidad mayor que la materia. Afectando tal hecho no solo a los miembros de la familia que reclaman por él, sino también a toda la sociedad civil que debe sentirse disminuida ante la desaparición de alguno de sus miembros. "Una sociedad no puede permitir que un individuo que ha formado parte de su propia sustancia, en la que ha impreso su marca, se pierda para siempre" (Hertz, 1990, p. 91).

En tal virtud, toda comunidad moral permite y protege la posibilidad del duelo, ya que por medio de él "se recobran las fuerzas, se vuelve a esperar y vivir, se sale del duelo, y se sale de él gracias al duelo mismo" (Durkheim, 1993, p. 630). 
En consecuencia, existen efectos por la desaparición y la ausencia del duelo, los familiares de las víctimas padecerán un duelo interminable, por lo que el papel del Estado frente al impacto del trauma social es insustituible e irrenunciable. Es la instancia que necesita el psiquismo como garantía social de su verdad, ya que el Estado, en su rol de administrador de la justicia, es tributario del cuerpo social en su conjunto.

El fundamento del derecho a la verdad, no es más que una re conceptualización de antiguas obligaciones del Estado y de derechos individuales, este principio de conocer el destino de los familiares y enterrar sus cuerpos aparece ya antiguamente en los pueblos judíos, griegos, romano e inclusive en la tradición cristiana.

El derecho a la verdad, denominado a veces derecho a conocer la verdad, en relación con las violaciones de derechos humanos está actualmente ampliamente reconocido en el derecho internacional. Así lo demuestran los numerosos reconocimientos de su existencia como derecho autónomo a nivel internacional y la práctica de los Estados a nivel nacional.

A nivel internacional, el derecho a la verdad en relación con las desapariciones forzadas o las personas desaparecidas se reconoce en diversos instrumentos. El artículo 32 del Protocolo I de los Convenios de Ginebra establece que "el derecho que asiste a las familias de conocer la suerte de sus miembros”. El artículo 24 de la Convención Internacional para la Protección de todas las Personas contra la Desaparición Forzada, dispone que, "cada víctima tiene el derecho de conocer la verdad sobre las circunstancias de la desaparición forzada, la evolución y resultados de la investigación y la suerte de la persona desaparecida. Cada Estado parte tomará las medidas adecuadas a este respecto".

Sin embargo, el derecho a la verdad no se limitó a esta faceta, sino que con el paso de las décadas fue abarcando otras violaciones graves de derechos humanos como la ejecución extrajudicial, el secuestro y la tortura. El derecho a la verdad ha sido reconocido de forma explícita en diversos instrumentos internacionales y por parte de mecanismos intergubernamentales en relación con la lucha contra la impunidad. 
El derecho a la verdad entrańa tener un conocimiento pleno y completo de los actos que se produjeron, las personas que participaron en ellos y las circunstancias específicas, en particular de las violaciones perpetradas y su motivación. En los casos de desaparición forzosa, desaparición de personas, nińos secuestrados o nacidos durante la cautividad de una mujer víctima de una desaparición forzosa, ejecuciones secretas y ocultación del lugar de sepultura de la víctima, el derecho a la verdad tiene también una faceta especial: el conocimiento de la suerte y el paradero de las víctimas.

El derecho a saber se refiere a las víctimas y sus familiares, al ser también un derecho colectivo tiene como finalidad que se conozca lo sucedido y se tomen medidas para que hechos tan lamentables no vuelvan a ocurrir en el futuro, ya que comprende, el deber de la memoria, encomendado al Estado con el fin de evitar que se produzcan distorsiones a la historia, pues el conocimiento, para un pueblo, de la historia de su opresión pertenece a su patrimonio y como tal debe ser preservado. Como señala Gómez Isa (2006, p. 38), "la verdad no se tiene que quedar en el círculo más íntimo de las víctimas, sino que tiene que ser reconocido social y públicamente, elevando así su validez al público y a la sociedad en su conjunto".

\section{EL DERECHO A LA VERDAD EN LA JUSTICIA TRANSICIONAL}

Ante las desapariciones forzadas o involuntarias, el derecho a la verdad en el marco de la justicia transicional debe ser plenamente exigible al Estado, quien debe asumir la obligación constitucional y convencional de prevenir, investigar, sancionar y reparar las violaciones a los derechos fundamentales.

El concepto de justicia de transición se ha convertido en un término de uso frecuente en el derecho internacional (ONU, 2004). Justicia transicional se refiere a las prácticas sociales y políticas para enfrentar desde la sociedad y desde el Estado legados de violaciones masivas o sistemáticas de los derechos humanos, en momentos de transición de la dictadura a la democracia o del conflicto a la paz (Méndez, 2013, p. 13).

El término justicia transicional alude a las experiencias de comisiones de la verdad, de procesamientos penales, de oferta de reparaciones a las víctimas, de reforma de 
instituciones que fueron vehículo de esas violaciones y también a esfuerzos desde la cultura para la preservación de la memoria histórica y su valoración (Méndez, 2013).

El concepto de justicia transicional adquiere significado e implicaciones particulares, que enfrentan la necesidad de equilibrar las exigencias muchas veces contrapuestas de paz y justicia:

El vocablo "justicia transicional" hace referencia a los procesos a través de los cuales se realizan transformaciones radicales de un orden social y político, bien sea por el paso de un régimen dictatorial a uno democrático, bien por la finalización de un conflicto interno armado y la consecución de la paz. Los procesos de Justicia Transicional enfrentan importantes dilemas, originados todos en la compleja necesidad de equilibrar los objetivos contrapuestos de justicia y paz (Uprimny, 2006, p. 2).

La justicia transicional busca dotar a las transiciones de justicia, es decir, enmarcar la política de las transiciones en ciertos estándares jurídicos, en particular aquéllos que se refieren a los derechos de las víctimas a la verdad, la justicia y la reparación ${ }^{3}$. Esto no significa que la justicia transicional aspire a lograr que el derecho conquiste o impere por completo sobre la política de la transición, pues se trata de un tipo especial de justicia determinado y limitado por las dinámicas políticas de los tiempos de transición. En ese sentido, aunque la definición de justicia transicional dista mucho aún de ser aceptada unánimemente y es objeto de debates intensos, la idea de que la justicia transicional consiste en una serie de mecanismos o procesos dirigidos a lograr un equilibrio entre el imperativo jurídico de justicia para las víctimas y la necesidad política de paz es ampliamente aceptada.

Es pertinente señalar, que los contenidos de la justicia como valor que el derecho debe realizar no son distintos por el hecho que se deben realizar en un contexto de

3 Existe una publicación periódica dedicada a la justicia transicional, International Journal of Transitional Justice. El International Center on Transitional Justice tiene su sede central en Nueva York y oficinas en lugares tan diversos como Ciudad del Cabo, Bruselas, Ginebra, Yakarta, Katmandú, Kinshasa, Beirut o Bogotá. Asimismo, existen el Oxford Transitional Research Group, el Transitional Justice Institute de la Universidad del Ulster, Irlanda, o el Center for the Study of Violence and Reconciliation en Ciudad del Cabo, Sudáfrica. 
transición. Como asevera Méndez (2013), no se trata de una justicia light, justicia de transición hace referencia a las dificultades, desafíos y oportunidades propias del momento transicional, no solo en momentos de transición de la dictadura a la democracia ni del conflicto a la paz, sino que son obligatorios para la sociedad y para el Estado, en tal virtud, la universalidad de las obligaciones jurídicas, aunque el momento transicional haya pasado, la obligación subsiste en el tiempo.

Frente a la comisión de un crimen como la desaparición forzada o involuntaria de personas, el derecho internacional plantea la necesidad de una reparación, que sea acorde a la magnitud de los derechos vulnerados. Por tal motivo el derecho internacional generó y desarrolló el concepto de reparación integral para las víctimas de estos crímenes.

La reparación integral, frente a la desaparición forzada de personas, es comprensiva de tres derechos de las víctimas:

a. Derecho a la verdad y al duelo: obligación estatal de investigar y dar a conocer los hechos, que se puedan establecer fehacientemente.

b. Derecho a la justicia: de procesar y castigar a los responsables.

c. Derecho a la reparación: de reparar los daños morales y materiales causados.

Cabe subrayar, que estas obligaciones no son alternativas sino de cumplimiento por separado. El Estado debe cumplir todas y cada una de ellas y si alguna se hace de cumplimiento imposible el resto sigue en pie. Así, frente a las violaciones masivas de derechos humanos, específicamente con relación al crimen de desaparición forzada de personas, se ha ido perfilando el derecho a la verdad, que en el estado actual implica, como correlato de aquéllas, una triple obligación por parte del Estado.

El derecho a saber se entiende como el derecho inalienable de todo pueblo a conocer la verdad sobre los acontecimientos pasados que conforman su historia, así como las circunstancias y las razones que llevaron a la violación masiva de los derechos 
humanos. Para Barahona de Brito (2002, p. 32) "la verdad" es el componente más importante de la justicia transicional; por el contrario, Pilar Domingo (2009, p. 83) dice que "la verdad es medio camino para la reconciliación, importante pero no suficiente. No podemos construir un país sin resolver el pasado violento. [...] Lo principal que se busca es una reconciliación en la sociedad".

El derecho a saber tiene sus fundamentos en una exigencia de carácter ético y moral, basada en el derecho a conocer con profundidad los hechos. Como sostiene Baltasar Garzón (2002, p. 43), "aun cuando ello suponga una catarsis colectiva que enfrente al Estado y a los ciudadanos a ese pasado" y que obligue a limpiar la herida y a la correcta sutura, si así no se hace jamás será posible la reconciliación.

El Estado tiene además, la obligación de preservar la memoria y la historia como patrimonio invaluable de la sociedad, entonces, al ser ella la dueńa de su pasado, nadie podría negarle el acceso a todo lo que contribuya a recuperarla, a hacer permanente el recuerdo, en virtud que la memoria colectiva no es un producto inmediato de la actividad social sino una construcción cultural muy elaborada, un valor e incluso una reivindicación social, inherente a la búsqueda de justicia sobre el pasado, el rescate del olvido y el desvelamiento de las biografías marginadas.(Aróstegui, 1998, p. 15)

Por lo anterior, podemos considerar que existirá paz social si se sabe que fue lo que sucedió, si la sociedad logra conocer la verdad acerca de los autores de esas violaciones. Tal actividad, constituye la base necesaria para construir una sociedad democrática, un verdadero Estado de derecho.

La búsqueda de la verdad, entendida en el doble sentido que le hemos venido dando, como un derecho que le pertenece tanto a las víctimas como a la sociedad, no se agota con la simple constitución y el trabajo llevado a cabo por una Comisión, con todas las limitaciones correspondientes como ser temporales y económicas. Sí constituyen una respuesta a estos sectores sociales, porque de hecho así se ha dado, pero no suplen la función del Poder Judicial en todo Estado democrático y de derecho. Debemos tener presente que la recuperación de la memoria a través de las Comisiones de la Verdad no es incompatible con la exigencia de Justicia (Garzón, 2002, p. 48). 
En todos los conflictos donde se han producido estos hechos, que tratamos como tema central, contrarios a la comunidad internacional en su conjunto, ha existido una constante: la impunidad.

Como lo hemos señalado, la lucha contra la impunidad presenta tres grandes objetivos, el primero de ellos es el conocimiento de la verdad, el segundo la realización de la justicia y el tercero la reparación. Los dos primeros dirigidos hacia las víctimas, en sentido estricto, y la sociedad, mientras que el tercero referido con exclusividad a la primera categoría nombrada, las víctimas.

La impunidad puede ser normativa, cuando un texto legal exime de pena a los criminales o bien fáctica cuando, no obstante existir leyes que penalizan ese tipo de accionar, los autores pueden liberarse de la sanción correspondiente por ejemplo por fallas en el funcionamiento del poder judicial. (Ambos, 1999, pp. 30-31)

El sujeto que aparece siempre detrás de la impunidad es el mismo: el Estado, a través de la actuación de sus distintos órganos de poder. Es él el encargado de revertir esta situación que atenta contra la dignidad del ser humano.

La Corte Interamericana de Derechos Humanos ha compartido esta preocupación desde hace muchos años, siendo un tema de reflexión constante, así se ha manifestado de forma expresa en contra de este fenómeno, definiendo la impunidad como

la falta en su conjunto de investigación, captura, enjuiciamiento y condena de los responsables de las violaciones de los derechos protegidos por la Convención Americana, toda vez que el Estado tiene la obligación de combatir tal situación por los medios legales disponibles ya que la impunidad propicia la repetición crónica de las violaciones de los derechos humanos y la total indefensión de las víctimas y de sus familiares.

En tal virtud, existe una obligación de los Estados que no es solo un imperativo legal y jurídico, sino también una exigencia ética de realizar una investigación seria y profunda sobre los hechos acontecidos y sobre quienes han sido los responsables. Esto último supone la investigación, persecución y consecuente castigo de quienes 
en un proceso, por supuesto con todas las garantías que reconoce hoy el derecho procesal, sean demostrados culpables (Garzón, 2002, p. 43).

El derecho a la justicia, es un derecho humano que corresponde no sólo a las víctimas directas de estos aberrantes delitos, sino también a la sociedad entera, quienes se han visto postergadas en sus derechos por un enemigo que recibe el nombre de impunidad ${ }^{4}$. Es decir, que la investigación y castigo de las violaciones a los derechos humanos no solo es un deber del Estado sino que constituye un derecho de las víctimas.

Efectivamente, existe la obligación del Estado de investigar, procesar y castigar a quienes resulten responsables; sin embargo, habrá que determinar si verdaderamente existe tal obligación y en su caso de dónde se deriva la misma.

Respecto al deber de los Estados de procesar a los presuntos autores de crímenes de lesa humanidad y garantizar el derecho de las víctimas, implica una debida instrucción desde la investigación, acusación, condena y consecuentemente la ejecución de la pena impuesta, se fundamenta en la existencia de una obligación general de respeto por parte de los Estados de los derechos humanos, obligación que se concreta en diversos instrumentos internacionales. Estos derechos son: el derecho a la vida, a la integridad física, a la libertad, a la seguridad personal.

El deber de penalización que recae sobre el Estado constituye una obligación suya, pero a la vez, un derecho de la víctima, es decir parte de su derecho a la reparación.

Los Estados, entonces, tienen una obligación, asumida vía convencional de respetar y la vez garantizar los derechos humanos. Esta última constituye un deber positivo que se traduce en un hacer por parte del Estado, hacer que implica en el caso de graves violaciones a los derechos humanos, tales como los crímenes de lesa humanidad una obligación de reparar pero no cualquier tipo de reparaciones sino una de tipo integral porque no hablamos de simples sino de graves violaciones. Esta reparación incluye el deber de enjuiciar y castigar.

4 Tal como sostiene Juan Méndez (2013), el derecho a la verdad es inseparable de un derecho a la justicia de contenido más general y que implica obligaciones de parte del Estado. 
Victoria Abellán (1993, p. 202) define esta obligación de administrar justicia como “aquel comportamiento asumido por el Estado que origina impunidad a través de la obstaculización, impedimento o perversión del funcionamiento de las instituciones encargadas de administrar justicia, cuando ellas son requeridas para conocer de hechos constitutivos de violaciones a los derechos humanos".

Este deber es el que sustenta el imperativo relativo a que los Estados deben investigar, procesar, castigar y, una vez condenados, ejecutar la pena impuesta a quienes resulten responsables de crímenes de lesa humanidad tales como, las desapariciones forzadas de personas.

El mensaje es que, la impunidad debe ser evitada, por todos los medios posibles y disponibles, sin olvidar que la impunidad viene siempre de la mano de alguno de los poderes del Estado nacional, pareciendo olvidar las obligaciones contraídas vía convencional e incurriendo de modo tal en responsabilidad internacional, y recordando que la impunidad genera aún más impunidad.

Con relación específica a la desaparición forzada de personas, la reparación consiste en que, "una vez dilucidada la suerte de la persona desaparecida, su familia tiene el derecho imprescriptible de ser informada y, en caso de muerte, el cuerpo le debe ser restituido después de su identificación y de que los autores hayan sido identificados, perseguidos o juzgados”.

El derecho a la reparación implica no sólo una indemnización de carácter pecuniario. En el caso de desaparición forzada de personas para satisfacer la lesión producida la reparación debe ser integral, conocer la verdad de los hechos que dieron lugar a violaciones de los Derechos Humanos, sus circunstancias específicas y la identidad de las personas que participaron en ellos, como parte del derecho a la reparación, en su modalidad no sólo de satisfacción sino también como garantía de no repetición.

Ahora bien, la búsqueda de la verdad y de la responsabilidad histórica no tiene su fundamento en el establecimiento de la democracia sino que lo encuentra en la dignidad humana, con lo que puede hablar de un derecho fundamental a la verdad. 
Por lo anterior, debe afirmarse que son reiterados los pronunciamientos que caracterizan el derecho a la verdad como un derecho imprescriptible, inalienable y de carácter autónomo cuya exigibilidad se asienta en su vinculación con otros derechos que, en relación con nuestro objeto de estudio, resultarían vulnerados ante la desaparición forzada. En este sentido, como ya lo hemos dicho, es deber del Estado realizar investigaciones eficaces a violaciones graves de los derechos fundamentales. Respecto a la negación del derecho a la verdad a los familiares de las víctimas, ha sido identificada por los órganos de protección internacional como una forma de sometimiento a tortura o malos tratos, en virtud de que el derecho de los familiares a conocer la verdad sobre la suerte y el paradero de la persona desaparecida no puede ser objeto de suspensión.

Para Correa (2007), refiriéndose a la autonomía o independencia del derecho a la verdad, es el mismo del esclarecimiento de la verdad y a los mecanismos de reparación. Se trata de una modalidad del derecho a recibir informaciones y en este contexto seńala que en teoría existen tres modelos institucionales de verdad en los procesos de paz, a saber: la verdad judicial en la que el juez decide, la verdad extrajudicial e institucional que es la verdad establecida por una comisión de la verdad y la verdad extrajudicial no institucional, que es la que surge en publicaciones académicas y de prensa. El derecho a la verdad, estaría satisfecho a través de todos los medios y no de uno solo de ellos, lo que indiscutiblemente consideramos, es utópico.

Recapitulando, el derecho a la verdad es fundamental tanto para las víctimas de las graves violaciones a los derechos humanos como para el conjunto de la sociedad, por lo que es imperativo proceder tanto al esclarecimiento de los casos individuales de violaciones de derechos fundamentales, como llegar a desentrañar los factores que han permitido el surgimiento, el desarrollo y la consolidación de la impunidad.

La Justicia Transicional se da en el marco de procesos coyunturales al interior de los cuales se busca la consecución de la paz y/o la consolidación de la democracia en sociedades que han afrontado conflictos armados y/o regímenes dictatoriales, en este sentido se entiende que uno de sus objetivos, si no el primordial es precisamente la consolidación del modelo democrático y/o de la paz. 
En esa medida los procesos de justicia transicional abordan la tarea de balancear dos necesidades que pueden verse contrapuestas en una negociación donde se busca lograr un acuerdo de paz y/o la consolidación del modelo democrático, siendo esta necesidad de un lado precisamente la paz y/o la democracia y de otro, las exigencias amparadas por el derecho internacional de verdad, justicia, reparación y garantías de no repetición.

Rodrigo Uprimny (2006) respecto a la finalidad de un proceso de Justicia Transicional refiere:

Los procesos de Justicia Transicional buscan, ordinariamente, llevar a cabo una transformación radical del orden social y político de un país, o bien para reemplazar un estado de guerra civil por un orden social pacífico, o bien para pasar de una dictadura a un orden político democrático. Especialmente cuando se trata de transiciones cuyo objetivo es dejar atrás un conflicto armado y reconstituir el tejido social, dicha transformación implica la difícil tarea de lograr un equilibrio entre las exigencias de justicia y paz, es decir, entre los derechos de las víctimas del conflicto y las condiciones impuestas por los actores armados para desmovilizarse (p. 11).

Para cumplir con esta finalidad no existe, como se ha dicho, una fórmula única y plenamente valedera para toda sociedad, que permita asumir estos procesos, donde se encuentran dos extremos, de un lado la impunidad absoluta frente a los crímenes cometidos y de otro el establecimiento de la verdad, la aplicación de la justicia y el otorgamiento de reparación a las víctimas.

Es aquí donde el Derecho Internacional Público y en especial el Derecho Internacional de los Derechos Humanos juega un papel preponderante, ya no es dable pensar que la necesidad de lograr la paz y la reconciliación y/o el establecimiento del sistema democrático sean fines que deban lograrse aun con el olvido de los actos atentatorios contra los Derechos Humanos cometidos, hoy en día los principios de verdad, justicia y reparación cobran un papel fundamental, no solo al interior de las sociedades sino en un aspecto global, donde es la sociedad humana la que hace estas exigencias. 
En este sentido, al interior de los procesos transicionales y si bien éstos se desarrollan en un contexto donde el fin último es indudablemente alcanzar la paz y/o la consolidación de la democracia, existen, aunados a este fin primordial, otros intereses que deben ser satisfechos, tales como son los que se han venido enunciando: la consecución de justicia frente a los crímenes cometidos, el establecimiento y el conocimiento público de la verdad de las graves violaciones a Derechos Humanos e infracciones al Derecho Internacional Humanitario, que hubieren tenido lugar durante el periodo de conflicto o de dictadura; el otorgamiento de reparaciones adecuadas y efectivas para las víctimas directas e indirectas; garantías de no repetición y la reforma de las instituciones estatales de manera tal que se permita la gobernabilidad democrática.

\section{JUSTICIA TRANSICIONAL: FUNDAMENTAL PARA LA DEMOCRACIA Y EL ESTADO DE DERECHO}

Reparar las injusticias del pasado cometidas a través de violaciones a derechos humanos no es sólo una obligación legal y un imperativo moral impuesto a los gobiernos. De hecho, la búsqueda de Justicia Transicional es una tarea urgente de la democratización, ya que resalta el carácter fundamental del nuevo orden que será establecido, un orden basado en el imperio de la ley, es decir, el estado de derecho y el respeto de la dignidad y valor de cada ser humano. Pero al mismo tiempo, es una de las decisiones más difíciles que cualquier democracia debe enfrentar, dado el esfuerzo por restaurar la verdad y la justicia donde la negación y la impunidad rigieron. (Méndez, 2013, p. 13)

Ya sea que se le asigne el significado de imperativo moral, obligación normativa o tarea inexcusable de la democracia, la justicia transicional, es indudablemente, una decisión complicada y es muy probable que se le acuse por actuar o por no hacerlo, ya que difícilmente se logrará dar la razón a todos. Sin embargo, después de que los gobiernos deciden dar el paso hacia la Justicia retrospectiva, la siguiente decisión que deberá tomar será aún más complicada pues implica trazar la línea de hasta dónde se pretende llegar. 
La Justicia Transicional es, según los criterios del Centro Internacional para la Justicia Transicional en definitiva, "una justicia adaptada a sociedades que se transforman a sí mismas después de un período de violación generalizada de los derechos humanos”, que tiene como objetivo el "reconocimiento de las víctimas y de la promoción de posibilidades de paz, reconciliación y democracia”.

La acepción "justicia transicional" no se refiere solamente al juzgamiento de los acusados ni concierne únicamente al Poder Judicial de un Estado, o a las víctimas de las vulneraciones de derechos humanos, sino a toda la sociedad. Muchas veces se le equipara a condena, cárcel u otro tipo de pena, cuando la sanción a los responsables de las violaciones a derechos fundamentales, esta es solamente una parte del conjunto de decisiones a tomar, como otras que deben ser llevadas a cabo: la averiguación de la verdad, la reparación y la reforma institucional.

El éxito de la Justicia Transicional y de la consolidación democrática se encuentra íntimamente relacionado con las medidas que se adopten en el momento y modo en que se haga. Si bien el juicio y condena a los responsables constituye una parte importante de estos mecanismos, que refuerza la idea del respeto a los derechos de todos los ciudadanos y la igualdad ante la ley, debe estar acompañada de otros elementos que permitan que la democracia no solamente sea estable sino sólida.

Una vez que las sociedades o el Estado responden la pregunta inicial de si se hará algo respecto a las vulneraciones del pasado o se "pasará la página", surge un abanico de opciones intermedias. Entre la "justicia completa” o plena y la política de "borrón y cuenta nueva" hay muchas posibilidades de actuación, que pueden incluir una o varias de las medidas mencionadas anteriormente. Aunque como resalta el Presidente Emérito del International Center For Transitional Justice (Méndez, 2013) afortunadamente, parece haber un creciente consenso de que el pasado demanda algo de nosotros en situaciones de transición. El debate más substancial es sobre qué es exactamente lo que se requiere, cuáles son las opciones, y cómo deberíamos solucionar las consecuencias éticas, legales, y políticas de esas decisiones. (pp. 13-15) 
Juan Méndez (2013, p. 15) habla de la "justicia completa" como uno de los extremos dentro de una línea imaginaria de opciones de decisión respecto a las políticas de verdad, justicia y reparación.

Por otro lado, analizando las implicaciones de lo que se conoce como el olvido total o política de perdonar y olvidar (Forgive-and-forget), borrón y cuenta nueva (clean slate) o de enterrar el pasado, surgen varios cuestionamientos. Dado que el olvido muchas veces es justificado como la mejor medida para no "remover las heridas del pasado" y para evitar sacar a la luz los rencores entre los agresores y las víctimas o entre miembros de distintos bandos, habría que preguntar si efectivamente logra dejar atrás las graves tensiones del pasado, si genera reconciliación o simplemente estabilidad y si esa supuesta estabilidad es sinónimo de éxito en la transición y en la consolidación democrática.

Si bien, posiblemente no se logre responder todas estas preguntas, pues son temas que permanecen en debate y dependen del contexto de cada país, lo cierto es, que es casi imposible hablar de total olvido o justicia plena.

Renunciar a "hacer justicia" bajo el pretexto de buscar estabilidad de la democracia posiblemente logre una solución temporal, pues probablemente, los conflictos que dieron lugar a la ruptura de la democracia y los que se generaron durante el período autoritario continuarán latentes si no son abordados, discutidos y resueltos; lo que puede generar que en el momento menos pensado vuelvan a manifestarse y explotar.

En definitiva la justicia transicional es una cuestión de equilibrio: en la persecución, en la asignación de responsabilidades, en las exigencias de una y otra parte, en el respeto de los derechos de las víctimas y de los acusados, entre los poderosos y los débiles. Pasa por una cuestión de poder, de establecer reglas claras que todos deban cumplir por igual y fijar límites al poder para evitar nuevos abusos. La justicia transicional debe buscar el justo medio, el punto clave en el que no se busque y sancionar a quien sea, por mostrar que se está haciendo justicia. Por otro lado la "búsqueda de la paz" no puede permitir el olvido y la impunidad, no se puede pasar la página y pretender que todos los conflictos se hayan solucionado ni tampoco fingir que con un apretón de manos las desigualdades, injusticias y autoritarismos serán borrados de la memoria, estarán solucionados y todo 
volverá a la normalidad. No se puede decir que con ello ya se consiguió la democracia y exigir a las víctimas que se den por satisfechas. Un país que niegue las luchas y abusos del pasado o busque que caigan en el olvido, se está negando a sí mismo.

Un marco de justicia transicional exitoso requiere ser equilibrado, como acertadamente afirma Méndez (2013), debe ser:

ética y políticamente informado, apuntando simultáneamente las necesidades de las víctimas de la represión, asegurando que los militares permanezcan subordinados a la autoridad civil, así como fortaleciendo las instituciones y los principios que sostienen a un Estado Democrático. Debe encontrar un equilibro entre las demandas morales maximalistas, cuya tendencia es extender los límites políticos, y las demandas minimalistas, cuya tendencia es reafirmar el poder de esos límites. No debe ser un arma en la lucha por el poder, sino una herramienta para la reconciliación; no debe ser usada para aplastar a los oponentes, sino como una forma de re-estabilizar un equilibrio perdido entre diferentes fuerzas sociales y políticas (pp. 16-21).

\section{A MANERA DE CONCLUSIONES}

El derecho a conocer la verdad respecto de los hechos que dieron lugar a violaciones de derechos fundamentales es, a la par, la obligación de investigación y sanción que el Estado mexicano asume y está obligado a cumplir a cabalidad.

Constitucionalmente, la obligación de garantía a los derechos fundamentales comprende la obligación del Estado de prevenir, investigar, sancionar y reparar las violaciones a tales derechos; en virtud de que el derecho a la verdad constituye una forma de reparación a los familiares de las víctimas de violaciones de derechos fundamentales, y puede contribuir a la disminución de la impunidad.

La desaparición forzada de personas constituye quizá la violación más perversa de los derechos humanos, siendo la negativa del derecho de un individuo a existir, a tener una identidad, convirtiendo a una persona en un ser no existente, la consecuencia 
que se puede observar, es que el desaparecido, oficialmente no existe, ni vivo, ni muerto, ni en prisión, ni en libertad, quedando sustraído a la protección de la ley, es decir, que es víctima de una verdadera privación de justicia. Es el grado más avanzado de corrupción y de abuso del poder del que se pueden valer las autoridades a cargo del cumplimiento de la Ley.

El problema de la criminalidad es muy serio y afecta de manera directa o indirecta a un porcentaje importante de la población, una mayor presencia de los derechos fundamentales en el debate público nacional supone la necesidad de revisar y realizar ciertas modificaciones en el quehacer de los aparatos policíacos, judicial y político.

Los tratados internaciones obligan a los Estados a tomar todas las medidas que estén a su alcance para cumplir con lo señalado en los propios tratados, por lo que nuestro país, al suscribir y ratificar las Convenciones Americana e Internacional contra la Desaparición Forzada de Personas, así como las Convenciones de Palermo y Mérida debe combatir la delincuencia organizada y la corrupción, a fin de atender el problema de impunidad y alcanzar los estándares internacionales de seguridad y acceso efectivo a la justicia.

La desaparición forzada es una conducta tipificada solo en 17 de 32 entidades en nuestro país: Aguascalientes, Baja California, Campeche, Chiapas, Coahuila, Colima, Chihuahua, Distrito Federal, Durango, Guanajuato, Guerrero, Jalisco, Nayarit, Nuevo León, Oaxaca, Puebla y San Luis Potosí. Los Estados de Guerrero y Chiapas derogaron de su Código Penal el delito de desaparición forzada y crearon una Ley específica sobre la prevención y sanción de este delito.

Las entidades que han incluido en sus códigos penales este delito, lo elevaron a categoría de grave y se sanciona en promedio con entre 10 y 50 años de cárcel, en ningún caso se permite libertad bajo fianza y en todos se incluyen además multas que van desde los 100 a los 8,000 salarios mínimos (entre 6,500 y 520 mil pesos). Familiares de víctimas consideran que si la pena fuera generalizada habría menos impunidad por parte de los agentes, entre ellos policías y elementos del Ejército. 
El Estado ha justificado desapariciones forzadas como consecuencia de las acciones emprendidas en la administración federal pasada, dentro de la guerra contra el narcotráfico, y la sociedad es cada vez más apática, hemos perdido la capacidad de asombro ante los cadáveres descuartizados y fosas clandestinas, asombro que debería derivar en rabia, cólera y vergüenza sobre todo, a las víctimas de sus horrendos crímenes.

Un porcentaje significativo, por no señalar que la mayoría de la sociedad mexicana no muestra un total rechazo de la atrocidades llevadas a cabo por "grupos del crimen organizado" ni de sus probados vínculos con agentes del Estado, ya es tiempo de que la conciencia y el conocimiento de tanta aberración e injusticia nos obligue a todos al compromiso de que esta situación se convierta en una sangrienta anécdota más de la historia.

El gobierno federal en febrero de 2013 dio a conocer una base de datos de 26 mil 121 personas desaparecidas o no localizadas en el periodo comprendido de diciembre de 2006 a diciembre de 2012. Y aunque el gobierno federal de Enrique Peña Nieto ha reconocido la magnitud de las desapariciones que tuvieron lugar durante el gobierno anterior y para poner en marcha algunas medidas destinadas a mejorar la búsqueda de las víctimas e investigar a los responsables, expidió la Ley General de Víctimas publicada con fecha 9 de enero de 2013 y creó la unidad de búsqueda de personas desaparecidas, dependiente de la Secretaría de Gobernación, no obstante, todavía no se ha reconocido el grado de implicación de agentes estatales en las desapariciones forzadas, y esta práctica se sigue dando.

Se han establecido ya los fundamentos del derecho a la verdad como derecho humano autónomo e inalienable, vinculado a la obligación y al deber de los Estados de proteger y garantizar los Derechos Humanos, realizar investigaciones eficaces y velar porque haya recursos efectivos y se obtenga reparación. Derecho este que se encuentra estrechamente vinculado con otros derechos tales como el derecho al acceso a la justicia, a las garantías judiciales y el derecho a solicitar y obtener información; de la misma forma se ha enfatizado la dimensión tanto individual como colectiva que tiene este derecho, que ha de considerarse como un derecho que no admite suspensión y no debe estar sujeto a restricciones. 
Igualmente, se ha señalado cómo este derecho debe ser garantizado al interior de los procesos transicionales al afrontar el pasado de graves violaciones a Derechos Humanos y al Derecho Internacional Humanitario, siendo el establecimiento y conocimiento público de la verdad sobre las causas generadoras de estas violaciones, las circunstancias de tiempo, modo y lugar en que se presentaron, así como de los autores y partícipes de las mismas, uno de los fines a alcanzar al interior de los procesos de Justicia Transicional.

Se puede afirmar que no existe un modelo único establecido de Justicia Transicional, y que, las sociedades que afrontan esta clase de procesos, si bien deben aprender de las experiencias anteriores, deben igualmente evitar recurrir a fórmulas únicas, iguales para todos, y a no importar modelos extranjeros, es por medio de la evaluación de las condiciones particulares que presenta cada sociedad, y la participación de todos los actores sociales que se debe establecer el modelo apropiado de justicia transicional aplicable a cada caso concreto.

La necesidad de establecer públicamente la verdad al interior de procesos transicionales se sostiene sin importar qué modelo o mecanismo de Justicia Transicional sea el que se adopte durante el proceso de transición, atento a que el derecho a la verdad, que tienen las víctimas y la sociedad en general no tiene obstáculo para su plena garantía.

Las dimensiones jurídicas, políticas, filosóficas, éticas y económicas deben ser consideradas en la toma de decisiones cuya implementación se diseña y propone, con el objetivo de luchar contra la impunidad y lograr la protección de los derechos de las víctimas de violaciones graves a los derechos fundamentales.

Justicia, paz, perdón, reconciliación, memoria y olvido se conjugarán en los discursos políticos y en sus reflejos normativos para legitimar tanto el intento de pasar la página y dejar atrás el pasado, como el enjuiciamiento de los presuntos responsables de aquellas violaciones. Cabe afirmar, que el derecho internacional de los derechos humanos habría asumido como función propia la de guiar al Estado en esta tarea de consolidar una paz justa y duradera, ya que varios Estados se han adentrado en procesos transicionales que, con sus variantes, tratan de afrontar las consecuencias 
de la comisión en el pasado de violaciones graves de los derechos humanos. (Pérez, 2013, pp. 55-57)

Bajo esta tesitura, no se permitiría al Estado elegir entre garantizar los derechos de las víctimas de las violaciones graves de los derechos humanos producidas en esos contextos o el derecho a la paz al que legítimamente aspira la sociedad que ha sobrevivido a esas experiencias. Se asume, que la paz solo será real y justa a largo plazo si se ha enfrentado la situación de las víctimas, a través de la satisfacción de sus derechos a la verdad, la justicia y la reparación, con ello, no se posterga la protección de los derechos de las víctimas, sino que la privilegia, entendiendo que se trata de un medio para construir la paz y consolidar la democracia y el Estado de derecho. 


\section{REFERENCIAS}

Abellán, H. (1993). Impunidad de violación de los derechos fundamentales en América Latina: Aspectos jurídicos internacionales, en La escuela de Salamanca y el Derecho internacional en América. Del pasado al futuro, A. Mangas Martín (Ed.), Salamanca.

Alexy, R. (2006). "Ponderación, control de constitucionalidad y representación” en Jueces y ponderación argumentativa, México, UNAM-Instituto de Investigaciones Jurídicas.

Ambos, K. (1999). Impunidady Derecho Penal Internacional, Buenos Aires, Ad Hoc., 2a. Ed.

Aróstegui, J. (1998). La historia vivida, Madrid, Alianza.

Atienza, M. y Ferrajoli, L. (2005). Jurisdicción y argumentación en el Estado constitucional de derecho, México, UNAM-Instituto de Investigaciones Jurídicas.

Brito, A. B., Fernández, P. A., \& Enríquez, C. G. (2002). Las políticas hacia el pasado. Madrid, Istmo.

Benda, E. y Hesse, C., et al. (2001). Manual de Derecho Constitucional, Madrid, Marcial Pons.

Comisión Interamericana de Derechos Humanos, $62^{\circ}$ Periodo de Sesiones, Estudio sobre el derecho a la verdad, E/CN.4/2006/91.

Consejo de Seguridad de las Naciones Unidas, El Estado de derecho y la justicia de transición en las sociedades que sufren o han sufrido conflictos, Informe del Secretario General, S/2004/616, 3 de agosto de 2004.

Correa, N. R. (2007). Reinserción y Reparación Vniversitas, julio-diciembre, número 114, Colombia: Pontificia Universidad Javeriana, Disponible en: http://redalyc.uaemex.mx/ pdf/825/82511409.pdf. 
Chinchón, J. (2007). Derecho internacional y transiciones a la democracia y la paz: hacia un modelo para el castigo de los crimenes pasados a través de la experiencia iberoamericana. Madrid, Parthenon.

Domingo, P. (2009). Impacto de las experiencias autoritarias en la construcción de democrática y de ciudadania, Salamanca: Ediciones Universidad de Salamanca.

Durkheim, E. (1993). Las formas elementales de la vida religiosa, Madrid: Alianza Editorial.

Ferrajoli, L. (2006). Derecho y razón. Teoría del garantismo penal, trad. Perfecto Andrés Ibáñez et al., $8^{\mathrm{a}}$ ed., Madrid, Trotta.

(2006). Derechos y garantías. La ley del más débil, trad. Perfecto Andrés Ibáñez y Andrea Greppi, $5^{\text {a }}$ ed., Madrid, Trotta.

Garzón R., B. (2002). Cuento de Navidad: es posible un mundo diferente, Madrid, Ediciones de la Tierra.

Gómez, Isa, F. (2006). El derecho de las víctimas a la reparación por violaciones graves y sistemáticas de los derechos humanos, en El derecho a la memoria, Gómez Isa, director, Instituto de Derechos Humanos Pedro Arrupe de la Universidad de Deusto (Bilbao, País Vasco, España).

Habermas, J. (1989). Teoría de la acción comunicativa, Madrid, Taurus.

Häberle, P. (2006). Verdad y Estado constitucional, 1a. Ed., UNAM-Instituto de Investigaciones Jurídicas.

Hertz, R. (1990). La muerte, México, Alianza Editorial Mexicana.

Informe del Secretario General de Naciones Unidas de agosto de 2004, El Estado de Derecho y la Justicia de Transición en situaciones de conflicto y post-conflicto, UN Doc. S/2004/616. [En línea]. Recuperado de http://daccess-dds-ny.un.org/doc/UNDOC/ GEN/N04/395/29/PDF/N0439529.pdf. 
Jiménez, C., J. (1984). Estado social y democrático de derecho. Diccionario del Sistema Político Español, Madrid.

Méndez, J., E. (2013). Justicia de Transición en Desapariciones forzadas, represión politica y crimenes del franquismo, Edición de Rafael Escudero Alday y Carmen Pérez González, Madrid, Trotta.

Oliveira, A. y Guembe, M., J. (1998). La verdad, derecho de la sociedad, en La aplicación de los tratados internacionales sobre derechos humanos por los tribunales locales, Proyecto Regional de Justicia, DRALC, MDGD, PGNUD-CELS, Edición conmemorativa del 50 Aniversario de la Declaración Universal de Derechos Humanos, Compiladores : Martín Abregú - Christian Courtis, Argentina, Ed. Del Puerto, 2a ed.

Pérez, González., C. (2013). Derecho a la verdad y desapariciones forzadas durante la guerra civil y el franquismo: una perspectiva desde el derecho internacional. En Desapariciones forzadas, represión politica y crimenes del franquismo, Edición de Rafael Escudero Alday y Carmen Pérez González, Madrid, Trotta.

Primer Informe Anual el Grupo de Trabajo sobre Desapariciones Forzadas o Involuntarias del Consejo de Derechos Humanos de Naciones Unidas, párrafo 187, [en línea] Recuperado de http://www.ohchr.org/Documents/HRBodies/HRCouncil/RegularSession/ Session19/A-HRC-19-58-Add2_sp.pdf

Uprimny, R. (2006). Justicia transicional sin transición?: verdad, justicia y reparación para Colombia. Bogotá, DeJusticia-Antropos. 